\title{
Ultrasound for Critical Care Physicians: Sickle Cell Crisis
}

A 32 year old man was admitted a week earlier with sickle cell pain crisis with increasing dyspnea, oxygen desaturation and bilateral pulmonary infiltrates. He had a pulseless electric activity code blue and an ultrasound of the heart was obtained (Figure 1).

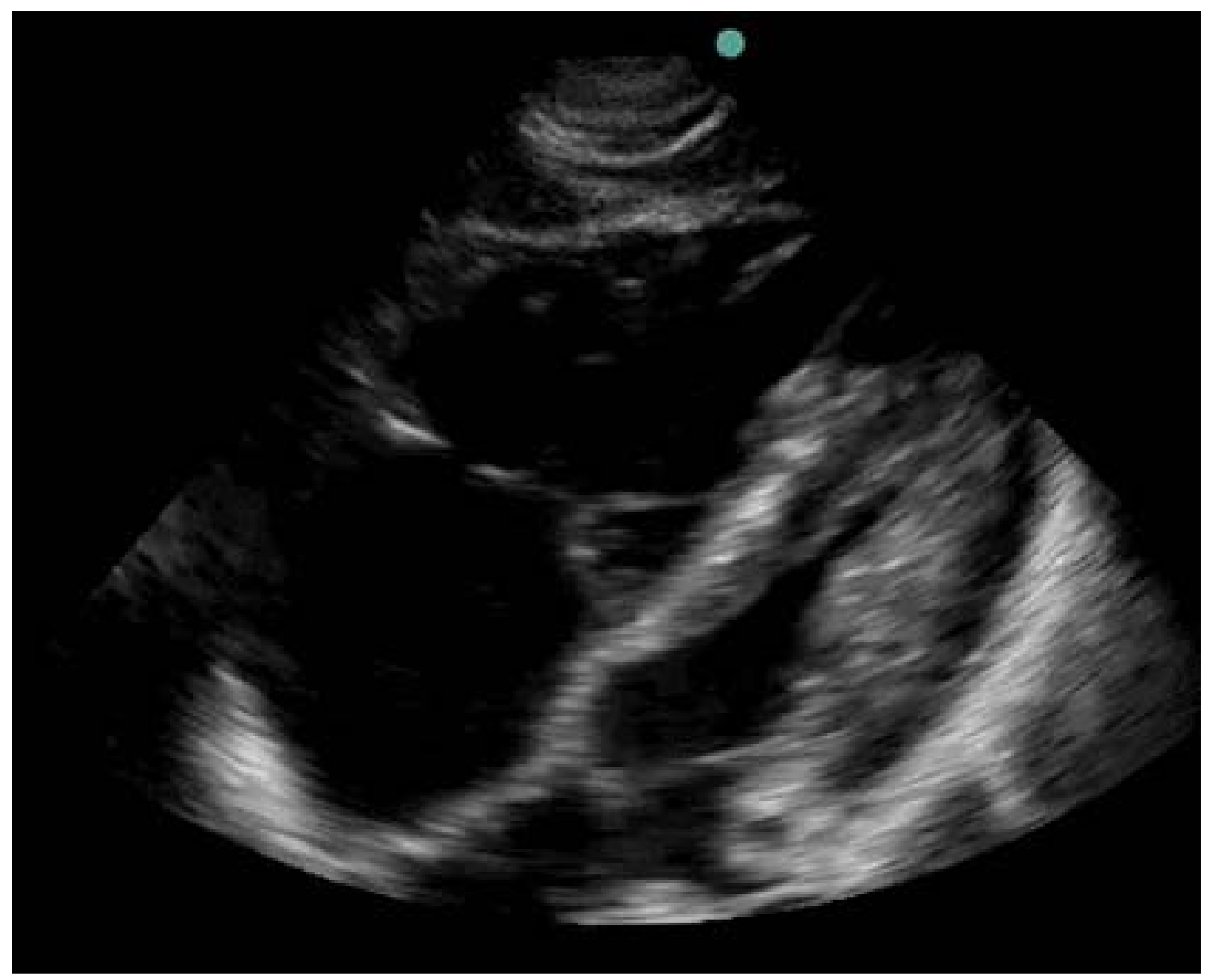

Figure 1. Subxiphoid view ultrasound of the heart.

What does the ultrasound show?

1. Aortic dissection

2. Aortic stenosis

3. Enlarged left ventricle (LV)

4. Enlarged right ventricle (RV)

5. Pericardial effusion 


\section{Correct! \\ 4. Enlarged right ventricle}

The RV is larger than the LV, hypocontractile, and that the intraventricular septum is abnormally shifted to the left (convex to the LV). The RV should be smaller than the LV. The right atrium (RA) is hugely distended.

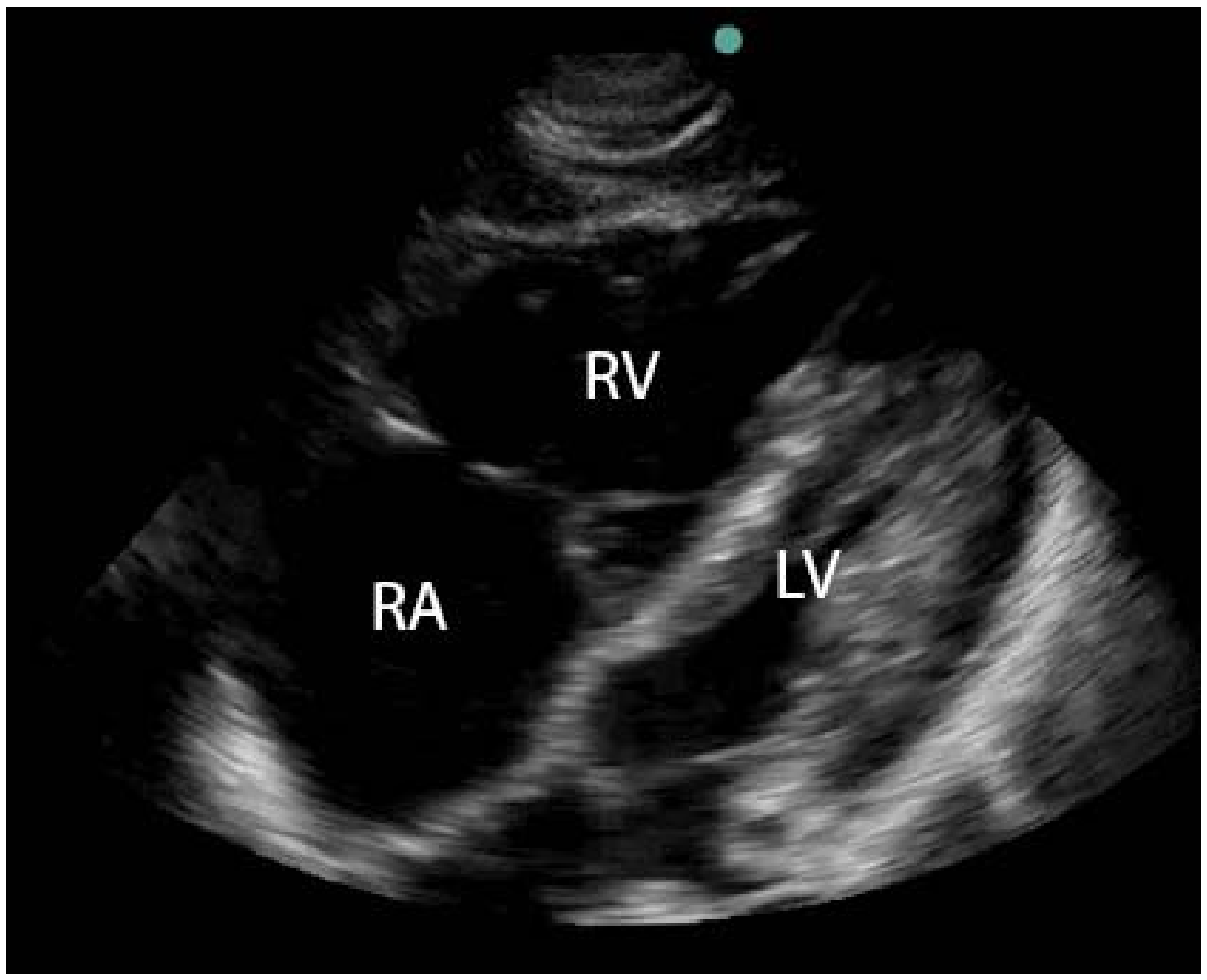

Figure 2. Subxiphoid view ultrasound of the heart showing an enlarged right ventricle (RV) and right atrium (RA). The RV is larger than the left ventricle (LV) and the interventricular septum is convex towards the LV which usually indicates high right-sided heart pressures.

It was determined that he likely arrested from acute right heart failure associated with sickle chest syndrome. He was treated with inhaled nitric oxide (NO) and a red cell exchange transfusion. He had no more cardiac arrests, but remained in shock. He eventually recovered without requiring further intervention such as extracorporeal membrane oxygenation (ECMO).

Robert A. Raschke, MD

\section{Reference}

1. Miller AC, Gladwin MT. Pulmonary complications of sickle cell disease. Am J Respir Crit Care Med. 2012;185(11):1154-65. [CrossRef] [PubMed] 